20 World Health Organisation Regional Office for Europe. Myocardial infarction community register. Copenhagen: WHO, 1976. (Public health in Europe No 5 .

21 Lardinoise CK, Neuman SL. The effects of antihypertensive agents on serum lipids and lipoproteins. Arch Intern Med 1988;148:1280-8.

22 Sever PS. Antihypertensive and adverse biochemical effects of bendrofluazide. BMI 1990;301:43.

23 Collins R, Peto R, MacMahon S, Herbert P, Fiebach NH, Eberlein ICA, et al. Blood pressure, stroke, and coronary heart disease. 2. Short-term reduction in blood pressure: overview of randomised drug trials in their epidemiological context. Lancet 1990;335:827-38.

24 IPPPSH Collaborative Group. Cardiovascular risk and risk factors in a randomized trial of treatment based on the beta-blocker oxprenolol: the international prospective primary prevention study in hypertension (IPPPSH). I Hypertens 1985;3:379-92.

25 Wilhelmsen L, Berglund G, Elmfeldt D, Fitzsimons T, Holzgreve H, Hosie J, et al. Beta-blockers versus diuretics in hypertensive men: main results from the HAPPHY trial. 7 Hypertens 1987:5:561-72.

26 Beta-blocker Heart Attack Trial Research Group. A randomized trial of propranolol in patients with acute myocardial infarction. I. Mortality results. FAMA 1982:247:1707-14.

27 Brown MA, Norris RM, Barnaby PF, Geary GG, Brandt PW. Effect of early treatment with propranolol on left ventricular function four weeks after myocardial infarction. Br Heart 7 1985;54:351-6.

28 MIAMI Trial Research Group. Metoprolol in acute myocardial infarction (MIAMI). A randomised placebo-controlled trial. Eur Heart f 1985;6: (MIAMI)

29 ISIS-I (First International Study of Infarct Survival) Collaborative Group. Randomised trial of intravenous atenolol among 16,027 cases of suspected acute myocardial infarction: ISIS-I. Lancet 1986;ii:57-66.

30 Intravenous beta-blockade during acute myocardial infarction. Lancet 1986;ii: 79-80.
31 Amery A, Birkenhager W, Brixko P, Bulpitt C, Clement D, Deruyttere M, et al. Mortality and morbidity results from the European working party on high blood pressure in the elderly trial. Lancet 1985 ; $1: 1349-54$

32 Coope J, Warrender TS. Randomised trial of treatment of hypertension in the elderly in primary care. $B M \mathcal{F} 1986 ; 293: 1145-51$.

33 Dahlof B, Lindholm LH, Hansson L, Schersten B, Ekbom T, Wester P. Morbidity and mortality in the Swedish trial in old patients with hyper tension (STOP-Hypertension). Lancet 1991;338:1281-5.

34 SHEP Cooperative Research Group. Prevention of stroke by antihypertensive drug treatment in older persons with isolated systolic hypertension. Final results of the systolic hypertension in the elderly program (SHEP). $\mathcal{F A M A}$ 1991;265:3255-64.

35 Pocock SJ, Hughes MD, Lee RJ. Statistical problems in the reporting of clinical trials. N Engl f Med 1987;317:426-32.

36 Dollery C, Brennan PJ. The Medical Research Council hypertension trial: the smoking patient. Am Heart f 1988;115(1):276-81.

37 Medical Research Council Working Party. Stroke and coronary heart disease in mild hypertension: risk factors and the value of treatment. $B M$ 1988;296:1565-70.

38 Cruickshank JM, Thorp JP, Zacharias FJ. Benefits and potential harm of lowering high blood pressure. Lancet 1987 ; i: 581 1-4.

39 Staessen J, Bulpitt C, Clement D, De Leeuw P, Fagard R, Fletcher A, et al. Relation between mortality and treated blood pressure in elderly patients Relation between mortality and treated blood pressure in elderly patients
with hypertension: report of the European Working Party on High Blood Pressure in the Elderly. BMf 1989;298:1552-6.

40 Samuelsson OG, Wilhelmsen LW, Pennert KM, Wedel H, Berglund GL. Th $\mathrm{J}$-shaped relationship between coronary heart disease and achieved blood pressure level in treated hypertension: further analyses of twelve years of follow up of treated hypertensives in the primary prevention trial in Gothenburg, Sweden. F Hypertens 1990;8:547-55.

(Accepted 27 November 1991)

\section{Victoria Infirmary \\ Langside, Glasgow \\ Keith Beard, FRCP,}

consultant geriatrician

Department of Medicine, Royal Postgraduate Medical School,

Hammersmith Hospital, London W12

Christopher Bulpitt, FRCP, professor of geriatric medicine

Department of Geriatric Medicine, Seacroft Hospital, Leeds

Hugo Mascie-Taylor,

MRCPI, consultant physician

Royal College of Surgeons in Ireland, Dublin 2, Republic of Ireland

Kevin O'Malley, FRCPI, professor of clinical

pharmacology

St Mary's Hospital Medical School, London W2

Peter Sever, FRCP, professor

of clinical pharmacology

\section{St Charles Hospital,} London W10 6DZ

Stuart Webb, MRCP,

consultant physician

Correspondence to: $\mathrm{Dr}$ Webb.

BMF 1992;304:412-6

\title{
Management of elderly patients with sustained hypertension
}

\author{
Keith Beard, Christopher Bulpitt, Hugo Mascie-Taylor, Kevin O'Malley, Peter Sever, Stuart Webb
}

Abstract

Objective - To assess the clinical benefits of treating hypertension in elderly patients and to derive practical guidelines regarding indications, goals, and forms of treatment. trials.

Design-Review of six published randomised

Results-Active treatment of hypertension in elderly patients was associated with significant improvements in several indices of cardiovascular morbidity and mortality, particularly the incidence of fatal and non-fatal strokes. On the basis of the trial data, combined systolic and diastolic hypertension was defined as a sustained systolic pressure $>160 \mathrm{~mm} \mathrm{Hg}$ and diastolic pressure $>90 \mathrm{~mm} \mathrm{Hg}$. There is convincing evidence that efforts should be made to reduce both systolic and diastolic pressures to below these levels in patients up to the age of $\mathbf{8 0}$ years. Isolated systolic hypertension was defined as a systolic pressure $>160 \mathrm{~mm} \mathrm{Hg}$ in the presence of a diastolic pressure $<90 \mathrm{~mm} \mathrm{Hg}$. Two trials reported benefit from the treatment of isolated systolic hypertension in patients up to the age of 80 , and further trials are underway to support or refute this recommendation. Diuretics have an established role in the management of hypertension in elderly patients; $\beta$ adrenoceptor antagonists have given variable results, and the benefits are less impressive than with diuretic based regimens. Newer agents show promise in the treatment of elderly patients, particularly in the presence of coexisting disease, but their effects on morbidity and mortality have not been evaluated in large randomised trials.

Conclusions-Diuretics rather than $\beta$ blockers are the treatment of choice for patients with uncomplicated hypertension, but combinations of drugs may be required in as many as $50 \%$ of patients.

\section{Introduction}

A wealth of clinical evidence supports the need to treat hypertension in patients under the age of 65 years. The strong predictive power of raised blood pressure for cardiovascular disease - in particular coronary heart disease, heart failure, and stroke - is firmly established, and many trials have confirmed the benefits of drug treatment. There has, however, been a persistent reluctance to treat hypertension in older patients. This has stemmed partly from a lack of evidence of benefit from large controlled trials and partly from fears that efforts to reduce blood pressure in elderly patients might do more harm than good. Treating hypertension in elderly patients presents many theoretical and practical problems. They are a group of survivors who may have taken years to "track" to hypertensive levels of blood pressure or who may have renal artery stenosis or other forms of secondary hypertension. Moreover, they often have relatively low diastolic pressures; it has been proposed that they may respond differently to treatment, and it is widely believed that they are more prone to side effects than younger patients.

Until recently, few trials had specifically looked at the clinical implications of treating elderly hypertensive patients, ${ }^{1.3}$ but in the past few months, however, the results of another three major studies have been published. ${ }^{+-6}$ The present article reviews currently available trial data to derive practical guidelines for the assessment and management of hypertension in elderly patients, particularly the indications for treatment, goals of treatment, and choice of appropriate antihypertensive agents.

\section{Materials and methods}

We looked at three trials published in the 1980s: the Australian trial of treatment of mild hypertension in the elderly (1981), ${ }^{1}$ the European working party on high blood pressure in the elderly (EWPHE) trial (1985), ${ }^{2}$ and Coope and Warrender's trial of treatment of hypertension in elderly patients in primary care $(1986)^{3}$; and three trials published in the past few months: the systolic hypertension in the elderly programme (SHEP), ${ }^{+}$the Swedish trial in old patients with hypertension (STOP-Hypertension), ${ }^{5}$ and the Medical Research Council (MRC) trial of hypertension in older adults. ${ }^{6}$ 


\begin{tabular}{|c|c|c|c|c|c|c|}
\hline & Australian' & EWPHE $^{2}$ & $\begin{array}{l}\text { Coope and } \\
\text { Warrender }\end{array}$ & SHEP & STOP-Hypertension & $\mathrm{MRC}^{\mathrm{n}}$ \\
\hline No of patients & 582 & 840 & 884 & 4736 & 1627 & 4396 \\
\hline Age range (years) & $60-69$ & $60-97$ & $60-79$ & $70-\geqslant 80$ & $70-84$ & $65-74$ \\
\hline \multicolumn{7}{|c|}{ Blood pressure entry criteria: } \\
\hline Systolic & $<200$ & $160-239$ & $190-230$ & $160-219$ & $180-230$ or $<180$ & $160-209$ \\
\hline Diastolic & $95-109$ & $90-119$ & $105-120$ & $<90$ & $90-120$ or $105-120$ & $<115$ \\
\hline $\begin{array}{l}\text { pressure at entry } \\
\text { Blood pressure goal: }\end{array}$ & $165 / 101$ & $182 / 101$ & $197 / 100$ & $170 / 77$ & $195 / 102$ & $185 / 91$ \\
\hline Systolic & & & $<170$ & $<160 / \downarrow 20^{\star}$ & $<160$ & $<160 /<150^{\star}$ \\
\hline Diastolic & $<90<80^{\star \star}$ & $<90$ & $<105$ & & 95 & \\
\hline \multicolumn{7}{|l|}{ Treatment: } \\
\hline Initial & Chlorthalidone & $\begin{array}{l}\text { Hydrochlorothiazide } \\
+ \text { triamterine }\end{array}$ & Atenolol & Chlorthalidone & $\begin{array}{l}\text { (1) Hydrochlorothiazide }+ \\
\text { amiloride } \\
\text { (2) Or Atenolol or } \\
\text { metoprolol or pindolol }\end{array}$ & $\begin{array}{l}\text { (1) Hydrochlorothiazide }+ \\
\text { amiloride } \\
\text { (2) Atenolol }\end{array}$ \\
\hline Add on & Various & Methyldopa & $\begin{array}{l}\text { Bendrofluazide } \\
\text { Methyldopa }\end{array}$ & Atenolol & $\begin{array}{l}\text { (1) Atenolol or metoprolol } \\
\text { or pindolol } \\
\text { (2) Hydrochlorothiazide } \\
+ \text { amiloride }\end{array}$ & $\begin{array}{l}\text { (1) Atenolol } \\
\text { (2) Hydrochlorothiazide }\end{array}$ \\
\hline \multicolumn{7}{|c|}{ Blood pressure obtained: } \\
\hline Treatment group & $143 / 87$ & $149 / 85$ & $162 / 77$ & $144 / 68$ & $167 / 87$ & $152 / 79$ \\
\hline Placebo group & $155 / 94$ & $172 / 94$ & $180 / 88$ & $155 / 71$ & $186 / 96$ & $167 / 85$ \\
\hline
\end{tabular}

${ }^{\star}$ Depending on entry systolic pressure.

$\star \star$ Initial goal $<90 \mathrm{~mm} \mathrm{Hg}$, reduced to $<80 \mathrm{~mm} \mathrm{Hg}$ after two years.

We analysed the trials' definitions of hypertension and methods of measuring blood pressure, and their findings on the effects of treatment of hypertension on reducing morbidity and mortality. We looked for thresholds of blood pressure and age for starting and continuing treatment and examined the therapeutic goals of the six trials. We also considered the practicalities of assessment, treatment, and follow up. Finally, we assessed various means of treating hypertension in elderly patients.

\section{Results and discussion}

DEFINITIONS OF HYPERTENSION AND BLOOD PRESSURE MEASUREMENT

Definitions of hypertension must clearly indicate whether both systolic and diastolic pressures should be raised, or only one, and if so which one. From the trials' entry criteria, goal pressures, and results we defined combined systolic and diastolic hypertension as a sustained systolic pressure $>160 \mathrm{~mm} \mathrm{Hg}$ together with a diastolic pressure $>90 \mathrm{~mm} \mathrm{Hg}$ and isolated systolic hypertension as systolic pressure $>160 \mathrm{~mm} \mathrm{Hg}$ together with a diastolic pressure $<90 \mathrm{~mm} \mathrm{Hg}$.

A sustained increase in blood pressure should be recorded before treatment is considered. Single casual measurements of blood pressure may be misleading, and recordings should be obtained on several occasions before decisions are made. Ideally, the same observer should measure blood pressure in a similar environment. For mildly raised blood pressure it is perfectly acceptable to follow a patient without pharmacological treatment for up to six months, but with higher levels of pressure, recordings should be obtained at shorter

TABLE II -Percentage change in event rates, six trials. Figures for references 1-3 are based on a review by Staessen et al"; intention to treat analyses are reported if published

\begin{tabular}{|c|c|c|c|c|c|c|}
\hline & Australian' & $\mathrm{EWPHE}^{2}$ & $\begin{array}{l}\text { Coope and } \\
\text { Warrender }\end{array}$ & SHEP & $\begin{array}{c}\text { STOP- } \\
\text { Hypertension }\end{array}$ & $\mathrm{MRC}^{n}$ \\
\hline \multicolumn{7}{|l|}{ Non-fatal events: } \\
\hline Stroke & -37 & -35 & -27 & $-37^{\star}$ & $-38^{\star}$ & -30 \\
\hline Myocardial infarction & +18 & NR & +11 & $-33^{\star}$ & -16 & NR \\
\hline All cardiac & -10 & -9 & -26 & $-40^{\star}$ & NR & -13 \\
\hline All cardiovascular & -26 & $-36^{\star}$ & -26 & $-36^{\star}$ & NR & $-25^{\star}$ \\
\hline \multicolumn{7}{|l|}{ Fatal events: } \\
\hline Stroke & -1 & -32 & $-70^{\star}$ & -29 & $-73^{\star}$ & -12 \\
\hline Cardiac & $-75 t$ & $-38^{\star}$ & +1 & $-20 \dagger$ & $-25 \ddagger$ & $-22 \dagger$ \\
\hline All cardiovascular & -61 & $-27^{\star}$ & -22 & -20 & NR & -9 \\
\hline All non-cardiovascular & +13 & +21 & NR & +5 & NR & +5 \\
\hline Total deaths & -23 & -9 & -3 & -13 & $-43^{\star}$ & -3 \\
\hline \multicolumn{7}{|l|}{ All events: } \\
\hline Stroke & -34 & $-36^{\star}$ & $-42^{\star}$ & $-36^{\star}$ & $-47^{\star}$ & $-25^{\star}$ \\
\hline Cardiac & -19 & -20 & -15 & $-27^{\star}$ & $-13 \ddagger$ & $-19+$ \\
\hline All cardiovascular & -24 & $-34^{\star}$ & $-23^{\star}$ & $-32^{\star}$ & $-40^{\star}$ & $-17^{\star}$ \\
\hline
\end{tabular}

$\mathrm{NR}=$ Not reported. ${ }^{\star} \mathrm{p}<0 \cdot 05$. †Ischaemic heart disease. $\ddagger$ Myocardial infarction. intervals to quickly establish the need for intervention.

The posture of the patient at the time of blood pressure measurement is important. ${ }^{7}$ Elderly patients may have considerable orthostatic falls in blood pressure. Although the formulation of a management plan for hypertension must clearly take into account falls in blood pressure on standing, most of the trials' data on the outcome of treatment are based on recordings taken in the sitting position..$^{2-4}$ The decision to treat hypertension in elderly patients should be based on the mean of several measurements of blood pressure recorded in the sitting position, provided there is no appreciable postural fall.

\section{AIMS OF TREATMENT AND TRIAL RESULTS}

The primary objective of controlling hypertension is to reduce the morbidity and mortality attributable to cardiovascular and cerebrovascular disease without increasing morbidity and mortality from other causes. Evidence that this objective can be achieved comes from several studies that investigated the effects of treating hypertension in elderly patients (table I). There are obvious differences in the age groups studied, the forms of treatment, and the methods used for assessing clinical outcome in these studies, but comparative assessment of the findings shows several trends (table II).

Treatment of hypertension tended to reduce the incidence of non-fatal stroke and cardiac events, and a significant decline in total non-fatal cardiovascular events was observed in three of the six trials. ${ }^{246}$ The studies were not designed primarily to detect a change in overall mortality, but a reduction was seen in each trial and this trend achieved significance in the STOPHypertension trial with a fall of $43 \%$. Some trials showed significant reductions in the number of cardiac deaths ${ }^{2}$ and stroke deaths. ${ }^{35}$

Total cardiovascular events were reduced significantly in five trials, ${ }^{2-6}$ with reductions of $17-40 \%$. This effect of treatment was attributable predominantly to significant falls in combined fatal and non-fatal strokes, ranging from $25 \%{ }^{6}$ to $47 \% .^{5}$ Though all trials showed a reduction in the combined rate of fatal and non-fatal cardiac events, this change reached significance only in the STOP-Hypertension trial.

Some of the trials reported side effects of drug treatment, either volunteered by the patients, collated by questionnaire, or evaluated by blood biochemistry. Adverse symptoms were reported as minor ${ }^{256}$ or were no different from symptoms in controls. ${ }^{3}$ Drug treatment with diuretics or $\beta$ blockers was associated with alterations in concentrations of blood glucose, uric 
acid, potassium, or cholesterol, but the overall differences were small. ${ }^{25}$

\section{INDICATIONS FOR TREATMENT}

Having established the potential benefits of treating hypertension in elderly patients, the next step is to consider how to apply this knowledge to clinical practice. As the trials showed improvement in morbidity and mortality for all blood pressure ranges above the lower limit of the trials' entry criteria, these values (table I) provide a reasonable indication of the threshold for treatment.

In the presence of combined systolic and diastolic hypertension, the trials showed benefits from intervention at blood pressures $>160 \mathrm{~mm} \mathrm{Hg}$ systolic and $90 \mathrm{~mm} \mathrm{Hg}$ diastolic, although there is as yet little evidence to support this strategy in patients aged over $80 .^{2}$ For isolated systolic hypertension, the SHEP study indicated benefit of intervention for patients of any age with isolated systolic blood pressure $>160 \mathrm{~mm} \mathrm{Hg}$. This strategy is supported in patients up to the age of 75 by subgroup analysis of the MRC trial. Further trials are under way to support or refute this recommendation. ${ }^{9}$ There is no evidence to indicate at what level of isolated diastolic hypertension patients should benefit from treatment, even though many such patients must have been included in the Australian study.

Overall, the evidence suggests that treatment should be considered for patients up to the age of 80 years with systolic pressure $>160 \mathrm{~mm} \mathrm{Hg}$ even in the presence of a diastolic pressure $<90 \mathrm{~mm} \mathrm{Hg}$. For older patients the trial data are less compelling. One subgroup of patients over the age of 80 in the EWPHE trial did not benefit from treatment, ${ }^{8}$ but benefits were apparent for this age group in the SHEP trial. ${ }^{4}$ The STOP-Hypertension study included patients up to the age of 84 , but the benefits of active treatment were negligible over the age of 80 and the findings applied only to those with relatively severe combined systolic and diastolic hypertension. There is thus insufficient evidence to recommend starting treatment over the age of 80 unless the blood pressure is greatly raised or complications such as congestive heart failure or angina are present. We are left with the problem of what to do with the elderly person receiving antihypertensive treatment, who reaches the age of 80 . One practical solution is to stop treatment for a trial period if the patient is normotensive. If hypertension recurs, treatment should be resumed. This strategy has yet to be subjected to formal evaluation.

\section{TREATMENT GOALS}

Five trials were based entirely ${ }^{2}$ or largely ${ }^{1356}$ on patients with combined systolic and diastolic hypertension. The data indicate that in most patients receiving active treatment, intervention successfully reduced blood pressure to the levels that were stated as the goals of these trials. As this reduction in blood pressure was associated with clinical benefit these goals could be adopted generally. Two of the trials ignored systolic blood pressure and aimed solely at reducing diastolic pressure to levels equal to or below the entry criterion for this variable. ${ }^{12}$ Coope and Warrender adopted the same approach for diastolic pressure, but additionally aimed at reducing systolic pressure to $170 \mathrm{~mm} \mathrm{Hg}, 20 \mathrm{~mm}$ below the minimum entry criterion. ${ }^{3}$ The remaining two trials aimed at reducing systolic blood pressure to less than $160 \mathrm{~mm} \mathrm{Hg}$ with the additional target of a diastolic pressure of less than $95 \mathrm{~mm} \mathrm{Hg}$ in the STOP-Hypertension trial. ${ }^{56}$

Taken together, these differing trial aims lead to the simple conclusion that the therapeutic goal for combined systolic and diastolic hypertension should be a reduction in blood pressure to levels below the treatment threshold of $160 / 90 \mathrm{~mm} \mathrm{Hg}$. The hypothesis that clinical benefit may be lost by reducing blood pressure to levels significantly below this value (the J shaped curve) remains to be evaluated.

In the case of isolated systolic hypertension, the only available treatment goals are those provided by the SHEP trial, in which the declared aim was a reduction in systolic blood pressure to $<160 \mathrm{~mm} \mathrm{Hg}$. For those patients with systolic blood pressures between 160 and $179 \mathrm{~mm} \mathrm{Hg}$, the aim was a reduction of at least $20 \mathrm{~mm} \mathrm{Hg}$.

PRACTICALITIES OF ASSESSMENT, TREATMENT, AND FOLLOW UP

In addition to blood pressure measurement, comprehensive clinical assessment is important before treatment is started. Particular attention should be paid to detecting conditions that might influence the choice of antihypertensive treatment. These include congestive heart failure, obstructive airways disease, diabetes, gout, peripheral vascular disease, poor mobility, urinary frequency, and incontinence. It is essential to measure serum creatinine concentration and electrolytes and to test urine for protein and glucose. Where cardiorespiratory disease is suspected - for example, in a patient who has dyspnoea or angina $-\mathrm{a}$ chest $x$ ray film and electrocardiogram should be obtained. Depending on the intended drug treatment, it is also desirable to measure uric acid, lipid, and glucose concentrations. It must be remembered, however, that diuretics, which affect these variables most adversely, have been shown consistently to be associated with a good outcome from treatment. . $^{-6}$

Patients should be seen monthly until the target blood pressure is achieved and then at three month intervals. Physical examination should be repeated annually and investigations where appropriate. If there is end organ damage or if there are multiple coexisting medical conditions it may be more appropriate for elderly patients with hypertension to be assessed at a hospital department, at least initially. (The decision to refer depends on many things, including the patient's general frailty and enthusiasm for hospital attendance.)

More general assessment of the patient is also important, including some evaluation of cognitive function, which may give some indication of the risks of non-compliance with an antihypertensive drug regimen, and this in turn may influence the choice of treatment. Urinary frequency and incontinence are important, particularly if treatment with a diuretic is contemplated. The prescriber may reach the conclusion that conditions other than hypertension - for example, dementia or malignant disease-dominate the clinical picture and may therefore feel that treatment should be withheld.

\section{TREATMENT OF ELDERLY HYPERTENSIVE PATIENTS}

\section{Non-pharmacological treatment}

Non-pharmacological measures that have become accepted practice in the management of younger hypertensive patients (weight reduction, exercise, moderate reduction in salt and alcohol intake) apply also to the older patient, either alone or in combination with drug treatment. ${ }^{10}$ However, more research is required to determine the ability of elderly people to change lifelong habits.

Although a modest reduction in salt intake has been claimed to have only a small effect in lowering blood pressure, such measures may be particularly beneficial in elderly patients, in patients with cardiac failure, and in combination with diuretics. Dietary potassium supplementation cannot be recommended solely for its effects on lowering blood pressure, but there is increasing evidence from epidemiological studies that a 
higher intake of dietary potassium protects against stroke, and for this reason alone it should be recommended.

Because of the strong association of hypertension with coronary heart disease, coexisting risk factors for coronary heart disease should also be assessed in elderly hypertensive patients, particularly cholesterol concentration and smoking habit.

\section{Pharmacological treatment}

In elderly patients the pathophysiological accompaniments of aging and hypertension may modify responses to drugs. Older hypertensive patients show lower stroke volume, cardiac output, and intravascular volume and higher peripheral vascular resistance than younger patients. Baroreceptor reflex function is impaired in elderly patients, and postural hypotension is common and may be exacerbated with drugs. Left ventricular hypertrophy, which is an important predictor of cardiovascular morbidity and mortality, is also common and is associated with increased ventricular ectopy, impaired coronary reserve, and sudden death.

Treatment may obviously be modified for individual patients according to the severity of the hypertension and the presence of associated cardiovascular or cerebrovascular pathology and other accompanying diseases. Indeed the stepped care approach generally advocated for hypertension is often not appropriate for elderly hypertensive patients, in whom multiple pathology and contraindications commonly coexist. Thus the drug must be chosen for the individual patient.

\section{Diuretics}

Diuretics have been the mainstay of treatment of hypertension in elderly patients, and in the major intervention trials diuretics have been shown to reduce cerebrovascular and in some instances cardiac complications: of the six trials discussed above, five used a diuretic as at least one first line treatment. ${ }^{124.6}$ Conventional doses (hydrochlorothiazide $25 \mathrm{mg}$ or equivalent) effectively lowered blood pressure when compared with placebo. Most of the drug induced fall in pressure can, however, be achieved with lower doses - for example, hydrochlorothiazide $12.5 \mathrm{mg} / \mathrm{day}$. There is little to choose between individual thiazides and chlorthalidone, but higher doses of thiazides or loop diuretics should be avoided in the absence of heart failure.

Adverse effects include hypovolaemia and postural hypotension (particularly with higher doses) as well as hypokalaemia, decreased glucose tolerance, increased serum urate and creatinine concentrations, and dyslipidaemia. Elderly patients may be more susceptible to thiazide induced hypokalaemia, and a case can be made for combining a lower dose of thiazide with a potassium retaining diuretic such as triamterene or amiloride. ${ }^{256}$ Thiazides should not be given to diabetic patients.

Adverse lipid changes induced by thiazides may be important in younger patients. Such changes may well be relevant in elderly patients but are overshadowed by the benefits of lowered blood pressure.

\section{$\beta$ Adrenoceptor blocking drugs}

$\beta$ Blockers have been extensively used in the past two decades and have been incorporated as first or second line agents in trials in elderly patients. ${ }^{3-6}$ There are theoretical grounds for suggesting that this class of agent is less than ideal in elderly subjects by virtue of their haemodynamic profile, particularly the reduction in cardiac output, which may already be compromised.
The effects of $\beta$ blockers on stroke and coronary heart disease have been observed in two trials. ${ }^{36}$ In neither trial were cardiac events prevented by atenolol, but the number of non-fatal strokes tended to be reduced. In the MRC trial, mortality from stroke and all cardiovascular causes was not reduced by treatment with a $\beta$ blocker. In the STOP-Hypertension trial, in which most patients receiving active treatment received one of three $\beta$ blockers, non-fatal and fatal strokes were prevented but treatment had no significant effect on cardiac events (myocardial infarction).

Although $\beta$ blockers cannot now be considered the treatment of choice in elderly hypertensive patients they may be advantageous in those with angina or a previous myocardial infarction.

As with many other classes of agents, lower doses of $\beta$ blockers may control blood pressure in many patients. In patients who experience symptomatic bradycardia with conventional $\beta$ blockers, drugs with partial agonist activity - for example, pindolol-may be tried. Side effects with $\beta$ blockers include lethargy, depression, fatigue with exercise, sleeplessness, nightmares, and cold extremities. Coexisting diseases such as heart failure, asthma, chronic obstruction of airways, and peripheral vascular disease severely limit the usefulness of $\beta$ blockers.

\section{Newer antihypertensive drugs}

None of the newer agents have been subject to definitive controlled trials of benefit in terms of preventing stroke and coronary heart disease, and the case for using angiotensin converting enzyme inhibitors, calcium entry blockers, or $\alpha$ adrenoceptor blockers must be reviewed in this light. Nevertheless, such drugs may be favoured on a number of theoretical and practical grounds, particularly when diuretics or $\beta$ blockers are contraindicated. They may have a major role in managing patients with coexistent disease, such as heart failure, ischaemic heart disease, chronic lung disease, and diabetes (table III).

TABLE III - Selection of antihypertensive drug treatment according to coexisting disease in elderly patients

\begin{tabular}{|c|c|c|c|c|}
\hline Coexisting disease & Diuretic & $\beta$ Blocker & $\begin{array}{l}\text { Calcium } \\
\text { blocker }\end{array}$ & $\begin{array}{l}\text { Angiotensin } \\
\text { converting } \\
\text { enzyme inhibitor }\end{array}$ \\
\hline None & ++ & + & + & + \\
\hline Heart failure & ++ & - & -- & ++ \\
\hline Angina & + & $+t$ & ++ & + \\
\hline $\begin{array}{l}\text { Asthma or chronic } \\
\text { obstructive }\end{array}$ & & & & \\
\hline airways disease & ++ & - & + & + \\
\hline $\begin{array}{l}\text { Peripheral vascular } \\
\text { disease }\end{array}$ & + & - & ++ & $-\star$ \\
\hline Gout & - & + & + & + \\
\hline Diabetes & - & - & + & ++ \\
\hline
\end{tabular}

$++=$ First line drug.

$+=$ Suitable alternative drug

* High proportion of patients with peripheral vascular disease will have occult renovascular disease.

\section{Conclusions}

There is now indisputable evidence that the active treatment of hypertension in the elderly is associated with significant improvements in cardiovascular morbidity and mortality. In absolute terms, the MRC trial shows that one stroke is prevented for every 285 years and one coronary event prevented for every 200 years of diuretic based treatment. These benefits are considerably greater than those conferred by treating younger patients (table IV).

On the basis of the trial data, the recommended threshold for intervention in patients aged between 65 and 80 years of age is a systolic pressure $\geqslant 160 \mathrm{~mm} \mathrm{Hg}$. Such clear cut recommendations are not yet possible 
TABLE IV - Number of patient-years of treatment necessary to prevent one stroke or one coronary event. Data from $M R C$ trials $^{\circ}$

\begin{tabular}{lcc}
\hline Drug treatment & $\begin{array}{c}\text { Younger patients } \\
\text { (mean age 52) }\end{array}$ & $\begin{array}{c}\text { Elderly patients } \\
\text { (mean age 70) }\end{array}$ \\
\hline & Stroke & \\
Treatment: & 566 & 286 \\
$\quad$ Diuretics & 1423 & 556 \\
$\beta$ Blockers & 833 & 370 \\
All treatments & Coronary event & \\
Treatment: & No benefit & 200 \\
Diuretics & No benefit & No benefit \\
$\beta$ Blockers & No benefit & 417 \\
All treatments & & \\
\hline
\end{tabular}

for older patients, but one trial has suggested that therapeutic benefit is maintained with increasing age, ${ }^{+}$ and consideration should be given to treating older patients with more severe hypertension, particularly if this is complicated by such conditions as heart failure or symptomatic ischaemic heart disease.

Treatment should always be started with low doses and doses increased only where indicated. For patients with uncomplicated hypertension the currently available evidence, particularly the MRC trial results, supports the choice of diuretics rather than $\beta$ blockers as first line treatment. The use of other therapeutic agents should be guided by the presence of coexisting disease. In individual patients, substitution of drugs is indicated when responses to initial treatment are poor or when adverse effects intercede. Combinations of drugs may be required in as many as $50 \%$ of patients, and they should be selected on the basis of complimentary modes of action.

We wish to acknowledge the support of our meetings by an educational grant from Bristol Myers Squibb.

1 Management Committee. Treatment of mild hypertension in the elderly. Med F Aust 1981;ii:398-402.

Amery A, Birkenhager WH, Brixko P, Bulpitt C, Clement D, Deruyttere M, $e t$ al. Mortality and morbidity results from the European working party on high blood pressure in the elderly trial. Lancet 1985;i:1349-54.

3 Coope J, Warrender TS. Randomised trial of treatment of hypertension in elderly patients in primary care. BMF 1986;293:1145-51.

4 SHEP Co-operative Research Group. Prevention of stroke by antihypertensive drug treatment in older persons with isolated systolic hypertension. fAMA drug treatment in

5 Dahlof B, Lindholm LH, Hanson L, Schersten B, Ekbom T, Wester P-O. Morbidity and mortality in the Swedish trial in old patients with hyper ension (STOP-Hypertension). Lancet 1991;338:1281-5.

6 Medical Research Council Working Party. MRC trial of treatment of hypertension in older adults: principal results. BMF 1992;304:405-12.

7 Petrie J, O'Brien E, Littler W, de Swiet M, Padfield P, Dillon M. Blood pressure measurement. 2nd ed. London: BMF, 1989.

8 Amery A, Birkenhager W, Brixko R, Bulpitt C, Clement D, Deruyttere M, et al. Efficacy of antihypertensive drug treatment according to age, sex, blood pressure, and previous cardiovascular disease in patients over the age of 60 . Lancet 1986;ii:589-92.

9 Amery A, Birkenhager W, Bulpitt C, Clement D, De Leeuw P, Dollery C, et al. Syst-Eur. A multicentre trial on the treatment of isolated systolic hypertension in the elderly: objectives, protocol and organisation. Aging 1991;3:287-302.

10 Potter JF, Beevers GD. Non-pharmacological reduction of blood pressure in the elderly. In: Amery A, Staessen J, eds. Handbook of hypertension. Vol 12. the elderly. In: Amery A, Staessen J, eds. Handbook of hypertensic

11 Staessen J, Van Hoof R, Fagard R, Amery A. Epidemiology of treated and untreated hypertension in the elderly. In: Amery A, Staessen J, eds. Handbook of hypertension. Vol 12. Hypertension in the elderly. Amsterdam: Elsevier, 1989:320-51.

12 Medical Research Council Working Party. MRC trial of treatment of mild hypertension: principal results. BMF 1985;291:97-104.

(Accepted 13 fanuary 1992)

\section{Liver transplantation in 100 children: Cambridge and King's College Hospital series}

Departments of Paediatrics and Surgery,

Addenbrooke's Hospital,

Cambridge

A Salt, FRACP, research fellow

G Noble-Jamieson, STATE

EXAM MED, research registrar

N D Barnes, FRCP, consultan

paediatrician

$\mathrm{K}$ Rolles, FRCS, lecturer in surgery

$\mathrm{N}$ Jamieson, FRCS, lecturer in surgery

P Johnston, FRACs, lecturer in surgery

$P$ Friend, FRCs, lecturer in surgery

R Y Calne, FRS, professor of surgery

King's College Hospital, London

A P Mowat, FRCP, professor in paediatric hepatology

Correspondence to: Dr N D Barnes, Department of Paediatrics,

Addenbrooke's Hospital,

Cambridge CB2 2QQ.

BMF 1992;304:416-21

A Salt, G Noble-Jamieson, N D Barnes, A P Mowat, K Rolles, N Jamieson, P Johnston, P Friend, R Y Calne

Abstract

Objective-To review the results of the Addenbrooke's and King's College Hospital children's liver transplantation programme.

Design-Retrospective analysis of the first 100 children to receive liver grafts at Addenbrooke's Hospital, Cambridge, from December 1983 to March 1990.

Setting-Addenbrooke's Hospital, Cambridge, and King's College Hospital, London.

Subjects - 153 children assessed for liver transplantation, of whom 22 died before a donor became available and 31 were considered unsuitable. 100 children received grafts, of whom 27 had second grafts.

Results-One year actuarial patient survival was $71 \%$, with $57 \%$ one year graft survival. In the last two years survival rates had improved considerably, with $86 \%$ of patients and $63 \%$ of grafts surviving for at least one year. Sixty five children were alive 12 to 86 months after transplantation; 63 were well and leading normal active lives and 56 had entirely normal liver function. Children's growth and development were essentially normal, with many showing remarkable catch up growth.

Conclusions - Liver transplantation offers children with terminal liver disease a high chance of a return to full quality life and normal development. Improved surgical and medical care have progressively improved survival. The timing of transplantation is critical but has been constrained particularly by the availability of donors and resources.
Introduction

The first successful orthotopic human liver transplantation was reported in 1967,' but the procedure has become widely accepted in the management of end stage liver disease only since $1983 .{ }^{2}$ In children, one year survival was less than $40 \%$ before $1980^{3}$ but has improved progressively, and good medium term results with normal growth, development, and quality of life have been achieved. ${ }^{45}$ The adult liver transplantation programme at Addenbrooke's and King's College Hospitals began in 1968, but a children's programme was not started until $1983,{ }^{6}$ when suitable donor organs began to become available after the benefits of the procedure were publicised on television. Of 349 liver transplants performed during December 1983 to March 1990, 127 were in 100 children under the age of 17 . We describe the outcome of these transplantations and discuss the reasons for improved survival over the past two years.

\section{Patients and methods}

During December 1983 to March 1990, 153 children were assessed for liver transplantation. Twenty two children died before a donor became available, and 31 were considered unsuitable for transplantation for reasons of tumour metastasis, parental refusal after discussion, or, before 1987, abnormal anatomy (such as absent inferior vena cava or blocked portal vein) or small size. One hundred children ( 40 boys and 60 girls) received grafts, three receiving combined liver and kidney grafts for oxalosis. Twenty seven received a 